\title{
Article
}

\section{Monitoring training loads in professional basketball players engaged in a periodized training programme}

Aoki, M.S., Ronda, L.T., Marcelino, P.R., Drago, G., Carling, C., Bradley, P.S., and Moreira, A.

Available at http://clok.uclan.ac.uk/14721/

Aoki, M.S., Ronda, L.T., Marcelino, P.R., Drago, G., Carling, C. ORCID: 00000002-7456-3493, Bradley, P.S., and Moreira, A. (2017) Monitoring training loads in professional basketball players engaged in a periodized training programme. Journal of Strength and Conditioning Research, 31 (2). pp. 348358. ISSN 1064-8011

It is advisable to refer to the publisher's version if you intend to cite from the work. http://dx.doi.org/10.1519/JSC.0000000000001507

For more information about UCLan's research in this area go to http://www.uclan.ac.uk/researchgroups/ and search for <name of research Group>.

For information about Research generally at UCLan please go to http://www.uclan.ac.uk/research/

All outputs in CLoK are protected by Intellectual Property Rights law, including Copyright law. Copyright, IPR and Moral Rights for the works on this site are retained by the individual authors and/or other copyright owners. Terms and conditions for use of this material are defined in the policies page. 


\section{Monitoring training loads in professional basketball players engaged in a periodized training programme}

Running Head: training loads and basketball

Marcelo Saldanha Aoki ${ }^{1}$, Lorena Torres Ronda ${ }^{2}$, Pablo Rebouças Marcelino ${ }^{3,4}$, Gustavo Drago $^{4}$, Chris Carling ${ }^{5}$, Paul S. Bradley ${ }^{6}$, Alexandre Moreira ${ }^{3}$

\section{AFFILIATIONS}

${ }^{1}$ School of Arts, Sciences, and Humanities, University of São Paulo, Sao Paulo, Brazil;

${ }^{2}$ Department of Health and Kinesiology, Exercise and Sport Nutrition Lab, Texas A\&M University, College Station, USA;

${ }^{3}$ Department of Sport, School of Physical Education and Sport, University of São Paulo, São Paulo, Brazil;

${ }^{4}$ Integrated Support Center for Athletes (CIAA) —Esporte Clube Pinheiros, São Paulo, Brazil;

${ }^{5}$ Institute of Coaching and Performance, University of Central Lancashire, Preston, UK;

LOSC Lille Métropole Football Club.

${ }^{6}$ School of Sport, Leeds Beckett University, UK.

Contact details for corresponding Author

Name: Alexandre Moreira

Institution: Department of Sport, School of Physical Education and Sport, University of São Paulo

Mail address: Av. Prof. Mello Moraes, 65, Cidade Universitária,05508-030, São PauloSP, Brasil.

Telephone: 551130918798

E-mail address: alemoreira@usp.brmailto: 


\section{Abstract}

The aims of this study were to investigate the dynamics of external (eTL) and internal (iTL) training loads during seasonal periods and examine the effect of a periodized training programme on physical performance in professional basketball players. Repeated measures for 9 players $(28 \pm 6 \mathrm{yr} ; 199 \pm 8 \mathrm{~cm} ; 101 \pm 12 \mathrm{~kg})$ were collected from 45 training sessions, over a 6-wk pre-season phase and a 5-wk in-season phase. Physical tests were conducted at baseline (T1), week 4 (T2) and week 9 (T3). Differences in means are presented as $\% \pm$ Confident Limits (CL). A very likely difference was observed during in-season compared to pre-season for the eTL variables measured by GPS: mechanical load (13.5 \pm 8.8$)$ and peak acceleration (11.0 \pm 11.2$)$ respectively. Regarding iTL responses, a very large decrement in TRIMP (most likely difference, $-20.6 \pm 3.8$ ) and in session-RPE training load (very likely

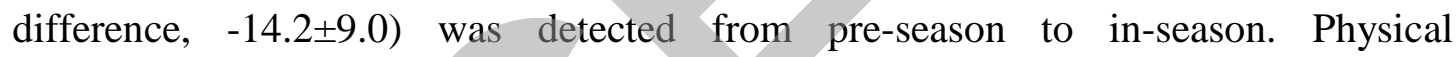
performance improved from $\mathrm{T} 1$ to $\mathrm{T} 3$ for: Yo-Yo Intermittent-Recovery Test 1 (62.2 \pm 34.3 , effect size [ES]>1.2); Countermovement Jump (8.8 $\pm 6.1, E S>0.6)$; and Squat Jump (14.8 \pm 10.2 , ES>0.8). Heart rate (HR; \% HRpeak) exercise responses during a submaximal running test decreased from $\mathrm{T} 1$ to $\mathrm{T} 3(3.2 \pm 4.3$, $\mathrm{ES}<0.6)$, as well as the HR recovery after the test $(14.7 \pm 8.8, E S>1.2)$. These results provide valuable information to coaches about training loads and physical performance across different seasonal periods. The data demonstrate that both eTL and iTL measures should be monitored in association with physical tests to provide a comprehensive understanding of the training process.

Key words: training load; periodization; performance; training monitoring 


\section{INTRODUCTION}

A major challenge in sport is to appropriately prescribe training loads (TL) in order to maximize athletes' physical performance while avoiding overtraining and/or injury, during the competitive season $(8,22,45)$. A general consensus is that appropriate periodization is a key factor in achieving optimal performance outcomes $(23,40,45)$. However, limited empirical evidence supports this statement in team sports (36).

Basketball is an intermittent team sport, which demands a wide range of physical requirements such as repeated sprint ability, and changes in running direction and speed, jumps, high-intensity running $(4,14)$. In order to maintain performance in these physical requirements, appropriate assessment and adequate periodization are essential. Akin to other team sports, monitoring TL in basketball is especially important as within team members, different responses to training sessions and matches occur. Given that basketball-specific actions involve whole-body displacement in forward, backward, lateral and vertical directions, accelerometerderived measures are, therefore, a useful approach to monitor external training load (eTL) in basketball players (42). However, there has been a paucity of research examining eTL in conjunction with internal training load (iTL) in basketball (42).

The monitoring of eTL measures derived from tri-axial accelerometers is now considered a yiable tool in team sports $(1,6,35)$. For instance, Boyd et al. (6) described the eTL of Australian football performed in official matches and training sessions, using a tri-axial accelerometer. More recently, Arruda et al. (1) suggested that accelerometer-derived measures might be used as an alternative method to assess eTL in soccer. Accelerometers have also been used for determining the demands of practice and competition in basketball players (35). While advancing knowledge of periodized eTL in team sports is of great importance, it is also imperative to recognize 
that eTL only describes the activity that a player has completed, and may not accurately depict the physiological stress imposed on individual athletes (30). Accordingly, internal TL (iTL) has been used to monitor an athlete's response to a training dose $(13,24,30-31,34,38,41)$. Taking into account the challenges in measuring the various types of stress encountered during training, the session rating of perceived exertion (session-RPE) method has been largely adopted $(13,24,30-31$, $34,38,41)$ to assess iTL. The session-RPE method has been validated for use in a number of team sports demonstrating strong correlation with both internal physiological responses $(22,38,44)$ and external measures of training load (17-18, $22,24,30)$. As such, further investigation is warranted to advance current knowledge in regards the association between eTL through accelerometer-derived measures, and iTL measures, during specific-basketball training sessions, across both pre- and inseason periods. This information may be used to design effective training strategies that may improve performance and reduce injury risk. Therefore, this study aimed to: (1) examine the effect of a periodized training plan on physical performance measures, and (2) describe TL (i.e., eTL using accelerometer-derived measures, and iTL through heart rate $[\mathrm{HR}]$ and session-RPE measures), associated with technical/tactical sessions, in professional basketball players during pre- and inseason periods.

\section{METHODS}

\section{Experimental Approach to the Problem}

The study was conducted during the 2014-15 competitive Brazilian Professional basketball season. Data were collected from 45 basketball-specific team-training sessions (i.e., technical and tactical sessions), performed across an 11-week period. 
The study period was divided into 2 phases: a) Pre-season phase (6-week period), and In-season phase (5-week period). The pre-season phase was divided into pre-season 1 and pre-season 2, with respect to the main technical/tactical training contents for each period. During the pre-season 1 period (week 1-3), 4 technical/tactical training sessions were performed per week, with a total duration ranged from 60-70 min per session. During the pre-season 2 period (week 4-6), 5 to 6 technical and tactical sessions were performed per week (duration range 80-100 min each). No matches were played during the pre-season. During the in-season period, session durations ranged from 70-80 min. Four technical and tactical sessions were performed per week, and the team competed in 2 games per week (i.e., Wednesday and Saturday). All on-court team-training sessions performed during the study period were considered for the present study. The physical conditioning sessions are described in order to illustrate the whole training periodization approach. Table 1 details the training content for each of the phases taking into account the technical/tactical and physical sessions. Table 2 shows the typical daily physical training exercises during pre-season $\left(1^{\text {st }}\right.$ and $2^{\text {nd }}$ period $)$ and in-season phases represented by week 2 , week 5 , and week 8, respectively. Physical performance tests were conducted at the beginning of the study (T1), after week 4 (T2), and after week 9 (T3).

\footnotetext{
*** Insert Table 1 around here $* * *$

*** Insert Table 2 around here $* * *$
} 


\section{Subjects}

A convenience sample of 9 professional male basketball players $(27.8 \pm 6.4 \mathrm{yr}$; stature: $199.1 \pm 8.3 \mathrm{~cm}$; body mass: $101.3 \pm 12.1 \mathrm{~kg}$ ) from an initial sample of 14 players were recruited from a professional team competing in the main State Basketball Championship and the National Brazilian League (NBB). The 5 players who did not participate in all training sessions during the study period were not included in the analysis. The assessed players were classified into 3 playing positions: point-guards $=2$; wings $=4$; centers $=3$. During the assessed in-season phase (week 7 - 11), the team participated in 10 official matches (5 away matches and 5 home matches). The team ended this investigated phase with 8 wins and 2 defeats. All 10 matches were played during the regular season (qualifying phase to playoffs), and the team was qualified in $1^{\text {st }}$ place, therefore, advancing to the playoffs. All players and coaches were informed about the research protocol in terms of requirements, benefits and risks. Their written consent was obtained before the study began. There were no players under the age of $18 \mathrm{yr}$ old. This research conforms to the ethical principles, which was approved by the local University Research Ethics Committee.

\section{Procedures}

\section{Technical and Tactical Training Sessions}

All training sessions were performed on the same regulation court under controlled environmental conditions. The usual verbal encouragement from the head coach and staff members was permitted during sessions. All training sessions started with a 15 min standardized warm-up based on running, technical skills (ball dribbling and layups), full-court offense drills (e.g. 3 vs $0 ; 3$ vs $2 ; 3$ vs 3 ), and dynamic stretching exercises. During the first period of the pre-season (weeks 1-3) the sessions were 
organized as follows: tactical drills without opposition ( 2 vs 0 to 5 vs 0 ) focusing on offensive aspects; tactical drills with opposition (1 vs 1 to 4 vs 4 ) focusing on defensive aspects and technical drills (e.g. shooting, passing). During the second period of the pre-season (weeks 4-6) the main content of the sessions was: tactical drills without the opposition ( 3 vs 0 to 5 vs 0 ), half-court scrimmage (4 vs 4 and 5 vs 5) and full-court scrimmage (4 vs 4 and 5 vs 5). During the in-season, the technical/tactical training sessions were very similar to those performed during the second period of the pre-season, however, the intensity and volume of the training sessions were constantly manipulated using iTL and eTL responses. The manipulation of the intensity included changes in the work/recovery ratio within and between exercises, varying the number of players performing full-court scrimmage exercises, changing rules (i.e size of court, number of players, playing with or without free shots, inclusion of repeated sprints after a given playing situation). For all training sessions (i.e., pre-season and in-season phases), players were allowed to consume water ad libitum during recovery periods.

\section{Physical Training Sessions}

All physical training sessions started with a specific warm up (i.e., light weightlifting exercises, jumps). During the first period of pre-season (weeks 1-3) 6 physical training sessions per week were performed with a mean duration of $\sim 90 \mathrm{~min}$; the main goal of this period was to develop athletes' strength. A secondary goal was intended to build speed/agility and endurance capacities. During the second period of preseason (weeks 4-6), 5 physical training session were performed per week, with a mean duration of $\sim 65 \mathrm{~min}$. During this period, the main goal was to develop the players' power, speed and agility; a secondary goal was to maintain the previous 
strength level achieved during the first period of pre-season (week 1-3). During the in-season (weeks 7-11), 3 sessions per week were performed with a mean duration of $\sim 60 \mathrm{~min}$. The main goal of this phase was to provide a sufficient stimulus to maintain the players' previously achieved level of fitness whilst providing recovery from technical/tactical sessions and matches.

Training load measures

The players' physical activity during each technical-tactical training session was monitored using a multivariable monitoring portable device (Bioharness ${ }^{\mathrm{TM}}$, Zephyr Technology, Auckland, New Zealand). Devices were placed on the middle of a players' chest. The players used the same unit across all training sessions.

Internal training load (iTL) measures

Heart rate (HR). Data were captured using a chest strap and reported as beats per min (b·min ${ }^{-1}$ ), and Banister's TRIMP values were also calculated (see Formula):

$t \times H R_{R} \times e^{1,92 \times H R_{R}}$

Where:

$t$ is training session duration in minutes

$e$ is base of the natural logarithm (2.712)

$H_{R}$ : reserve $H R$ is determined by the following equation:

$$
\mathrm{HR}_{\mathrm{R}}: \frac{H R s-H R E}{H R_{\max }-H R E}
$$

Where:

$\mathrm{HR}_{\mathrm{S}}$ is Session HR 
$\mathrm{HR}_{\mathrm{B}}$ is Rest $\mathrm{HR}$

$\mathrm{HR}_{\max }$ is Maximum $\mathrm{HR}$

The $\mathrm{HR}_{\max }$ values were obtained prior data collection by performing the Yo-Yo Intermittent Recovery Test Level 1, as previously done in basketball players $(34,41)$.

Physiological Load. This is a heart rate-based index, a value derived from the sum of all obtained physiological values (physiological intensity) from the training session, and the time spent at a given intensity zone. The intensity zone is determined based on the subject's maximum heart rate $\left(\%\right.$ of $\left.\mathrm{HR}_{\max }\right)$. The intensity level was classified from 0 to 10 as follows: $0 \leq 50 \% \mathrm{HR}_{\max } ; 1>50$ to $55 \% \mathrm{HR}_{\max } ; 2>55$ to $60 \% \mathrm{HR}_{\max }$; $3>60$ to $65 \% \mathrm{HR}_{\max } ; 4>65$ to $70 \% \mathrm{HR}_{\max } ; 5>70$ to $75 \% \mathrm{HR}_{\max } ; 6>75$ to $80 \%$ $\mathrm{HR}_{\max } ; 7>80$ to $85 \% \mathrm{HR}_{\max } ; 8>85$ to $90 \% \mathrm{HR}_{\max } ; 10>95$ to 100 or $>100 \% \mathrm{HR}_{\max }$. This zone classification system forms the basis of the analysis performed by the software (Bioharness ${ }^{\mathrm{TM}}$, Zephyr Technology, Auckland, New Zealand), and therefore adopted in the present study in accordance with manufacturer guidelines.

Session-RPE. Players' session-RPE were recorded $\sim 30$ min after each session using the Borg 10-point scale (CR-10 scale) (18). Session-RPE was derived by asking each player "How intense was your session?". Players were already familiarized with the CR-10 scale before this study. Daily training load (TL) was calculated by multiplying session-RPE by the session duration (18). The validity of using session-RPE for monitoring training and competition loads in basketball players has previously been demonstrated $(1,31,37-38)$. 


\section{External Training Load (eTL) measures}

In order to monitor Mechanical Load $(M L)$ and acceleration, players used the multivariable monitoring portable device (Bioharness ${ }^{\mathrm{TM}}$, Zephyr Technology, Auckland, New Zealand). The tri-axial accelerometer (piezoelectric technology) was a micro electro-mechanical sensor. It is sensitive along 3 orthogonal axes (vertical [x], sagittal $[\mathrm{z}]$ and lateral $[\mathrm{y}])$. Acceleration data were measured as gravitational forces (g) $(-3$ to +3 g) on each single axis or as Vector Magnitude Units (VMU), which is an averaged value of the previous 1 -s epoch (25-27). The reliability and validity of the Bioharness ${ }^{\mathrm{TM}}$ has been demonstrated in both laboratory and field based environments (25-27). Mechanical load (ML) is the accumulation of the mechanical intensity value over time. The mechanical load was measured using a vector magnitude unit (VMU; $\sqrt{ }\left(x^{2}+y^{2}+z^{2}\right) ;$ Where, vertical $(x)$, sagittal $(z)$ and lateral $\left.(y)\right)$. The time spent in each mechanical zone was considered for analysis. Intensity is defined according to the range into which the peak (in any axis) acceleration $g$ value fits in any 1 sec epoch. Value scaled linearly between $0.5(=0)$ and $3.0 \mathrm{~g}(=10)$ as following: $0=0.50 ; 1=$ $0.75 ; 2=1.00 ; 3=1.25 ; 4=1.50 ; 5=1.75 ; 6=2.00 ; 7=2.25 ; 8=2.50 ; 9=2.75 ; 10$ $=3.00 \mathrm{VMU}$.

\section{Physical assessments}

Submaximal Running Test. A submaximal 5 min running/5 min recovery test (7) was performed at the beginning of every testing session. All players were tested together with the intensity of the exercise bout fixed at $10 \mathrm{~km} \cdot \mathrm{h}^{-1}$ across $40 \mathrm{~m}$ shuttles. HR during exercise and during recovery were assessed as previously described using a harness (Bioharness ${ }^{\mathrm{TM}}$, Zephyr Technology, Auckland, New Zealand). Buchheit et al (8) demonstrated that HR during exercise is a useful variable for monitoring positive 
training responses during training and reported a 3.3\% coefficient of variation $(\mathrm{CV})$ for this measure largely affected by daily variations in training load, suggesting that this measure is a valid and highly reproducible measure.

Yo-Yo Intermittent Recovery Level 1 Test (Yo-Yo IR1). The Yo-Yo IR1 test was applied according to previously described methods in order to assess the players' aerobic and anaerobic capacity $(28,34)$. All players were familiar with the testing procedures. The players performed repeated $20 \mathrm{~m}$ shuttles, back and forth between the starting line and finish line marked by cones, at progressively increasing speeds dictated by an audio bleep emitting from a CD player. Between each shuttle, the players had a $10 \mathrm{~s}$ period of walking around a cone placed $5 \mathrm{~m}$ from the starting line. Failure to achieve the shuttle run on 2 successive occasions resulted in termination of the test. Total distance covered represented the test result. All tests were performed on the same basketball court where the players trained. The reliability of this test has been previously quantified with a coefficient variation of $\sim 5 \%$ (28).

Vertical Jumps. Players performed both countermovement (CMJ) and squat jumps (SJ). The CMJ was initiated from a standing position to a self-selected depth position and performed as quickly as possible with maximal effort. The hands were placed on the hips during the entire CMJ movement. While no restrictions were placed on the knee angle attained during the eccentric phase of the jump, players were instructed to maintain straight legs during the flight. The SJ was performed as a concentric only movement (i.e., no countermovement prior to takeoff) with hand placement on the hips to remove the effects of arm swing. The initial squat jump angle position was required to be at $90^{\circ}$ degrees. An adjustable bench was used as reference to keep the 
required SJ position angle. Three jumps were performed for each type of jump with a 2 min rest period between jumps. All jumps were conducted on an electronic jump mat (Ergojump Jump Pro 2.0 $0^{\odot}$ - CEFISE, Brazil). Jump mat technology provides valid measures of jump height compared to a criterion system $(r=0.97)(29)$ and pilot testing for the current study indicated that the jump mat system also provides reliable measures $(\mathrm{CV}<5.0 \%$; ICC > 0.90) for both SJ and CMJ.

Repeated Sprints Ability Test (RSA). The protocol adopted in this study was $12 \times 20$ m sprints with $20 \mathrm{~s}$ of active rest between sprints as used by Meckel et al. (33). A photoelectric cell timing system (Multisprint, Hidrofit ${ }^{\circledR}, M G-$ Brazil) was used to record the duration of each sprint (accuracy of 0.001s). Two sets of timing gates were used, one for the start (opening gate) and one for the end (closing gate). Players were instructed to decelerate only after the closing gate, and return to the start point to prepare for the next sprint. Although the return pace was chosen by each player, the instructor provided verbal feedback about the remaining recovery time. A standing start with the front foot placed $50 \mathrm{~cm}$ behind the opening gate was used for all sprints. All players received verbal encouragement during the test from instructors and coaches. The best sprint time (BT) and the mean sprint time (MT) were registered. The test-retest reliability previously reported for RSA total running time is 0.94 (16).

\section{Statistical Analyses}

Descriptive values are shown for technical/tactical and physical training loads performed over the 11 training weeks. A magnitude-based inferential statistical approach was adopted based on previous recommendations $(2,47)$. Parameters were $\log$-transformed to reduce bias due to the non-uniformity of error and analyzed using 
a customized Excel Spreadsheet (19-20). The effect size (ES) was calculated to determine the meaningfulness of the difference between pre- and in-season phases, corrected for bias using Hedges formula and presented with 90\% Confidence Limits [CL] $(2,12)$. The ES magnitudes were classified as trivial $(<0.2)$, small $(>0.2-0.6)$, moderate (>0.6-1.2) and large (>1.2). Smallest worthwhile differences were estimated from the standardized units multiplied by 0.2 . Uncertainty in the true differences of the scenarios was assessed using non-clinical magnitude-based inferences (21). Values are presented as means and standard deviations unless otherwise stated.

\section{RESULTS}

\section{Physical Test Performances}

Physical performance measures over the competitive season are presented in Table 3 and Figure 1. Large improvements in Yo-Yo IRT1 performance (difference in means; $\% \pm \mathrm{CL}=62.2 \pm 34.3 ; \mathrm{ES}>1.2)$ and a moderate-to-large increase in CMJ $(8.8 \pm 6.1$; $\mathrm{ES}>0.6)$ and $\mathrm{SJ}(14.8 \pm 10.2 ; \mathrm{ES}>0.8)$ performances were found from baseline $(\mathrm{T} 1)$ and after a 9-week period (T3). Small-to-moderate improvements in RSA test were observed from $\mathrm{T} 1$ to $\mathrm{T} 2(-2.7 \pm 1.5$, and $-1.9 \pm 2.3$; ES $<0.6$; for mean and best time, respectively). HRE response during the running test decreased from T1 to T3 (3.2 \pm 4.3; $\mathrm{ES}<0.6)$ as well as the $\operatorname{HRR}(14.7 \pm 8.8$; ES > 1.2).

*** Insert Table 3 around here $* * *$

*** Insert Figure 1 around here *** 


\title{
Overview of Weekly eTL and iTL
}

Descriptive values for technical and tactical iTL and eTL, and differences between pre- and in-season, are presented in Table 4. Mean training volume (min) between periods showed very large differences with lower values during the in-season phase ($22.8 \pm 1.8$ ). Regarding the iTL responses, this reduction (from pre-season to in-season) was accompanied by a very large decrement in TRIMP (most likely, $-20.6 \pm 3.8$ ) and in session-RPE training load (TL) (very likely, $-14.2 \pm 9.0$ ). However, the effect of such reduction was only trivial (unclear reduction; $-3.4 \% \pm 11.0$ ) for the physiological load measure. On the other hand, HR average and session-RPE showed increases from pre-season to in-season with a very likely and likely effect $(3.9 \pm 2.2$, and $8.3 \pm$ 9.3, respectively). Moreover, the mechanical load and peak acceleration (eTL measures) showed very likely differences with higher values for in-season phases $(13.5 \pm 8.8$, and $11.0 \pm 11.2$, respectively). The Figure 2 presents the training load performed over the 11-week microcycles during both pre- (week 1 to 6) and in-season (week 7 to 11) phases, for technical and tactical training sessions. Regarding the physical training, the descriptive values are presented in Table 5, and the iTL and session-RPE scores for physical training during the 11-week training period are displayed in Figure 3.

\author{
*** Insert Table 4 around here *** \\ *** Insert Figure 2 around here *** \\ *** Insert Table 5 around here $* * *$
}

*** Insert Figure 3 around here *** 


\section{DISCUSSION}

This study aimed to: (1) examine the effect of a periodized training plan on physical performance tests measures in professional basketball players during pre- and inseason phases and (2) describe eTL, using accelerometer-derived measures and the iTL associated with technical/tactical sessions. The main findings observed were a large improvement in Yo-Yo IRT1 performance and RSA, a moderate-to-large increase in jumping performance, and a decreased submaximal $\mathrm{HR}$ response to a 5 min submaximal run test. Moreover, training volume was higher during the preseason phase while mechanical load and peak acceleration values were greater during the in-season phase.

These findings have practical implications for coaches concerning the distribution of training content and strategies during pre- and in-season phases in basketball. While the improvement in Yo-Yo IRT1, RSA, and jump performances are associated with general training-induced adaptations, the improvements observed during the in-season phase suggest that these indicators might also be viewed as viable indicators of basketball-related physical performance measures, and that they might relate to competitive performance. It is noteworthy that the improvements in the present study are in accordance with previous findings (41). These authors assessed 19 elite female basketball players who were members of the Brazilian National team, preparing for the FIBA Americas Championship. The experimental design included one overloading period of 3-week in duration (weeks 4-6), followed by a 1-week tapering phase (week 7). The second overloading period was 3 wk in duration (week 8-10), followed by a 2-week tapering phase (weeks 11-12). Strength, jumping power, endurance and agility were assessed, and iTL and recovery stressstate were also quantified weekly. The results of this strategy revealed an 
improvement in strength and jumping performances from pre- to post-training. The speed, agility and intermittent endurance capacity also improved post-training.

It is noteworthy that the improvements observed in the present study, notably for Yo-Yo IR1 suggests the efficacy of the adopted present training periodization strategy. In the present study the observed difference in means (\% \pm CL) for Yo-Yo IR 1 from the beginning of the study to the $9^{\text {th }}$ week, was $62.2 \pm 34.3$ with the magnitude of the effect being classified as very likely. This effect is highly relevant taking account that it was observed for professional players with a 9-week training investigation. For example, the improvement is higher than that reported by Nunes et al. (41) after 12 training weeks $(E S=0.35)$ or in other team sport athletes such as those reported by Fanchini et al (15) with 11 soccer players whose Yo-Yo R1 performance increased $40 \%$ after training $(90 \% \mathrm{CI}=30.7-50.4 \%)$ within a 17 -week period investigation; the present improvement in Yo-Yo IR1 is also higher than that reported by Buchheit et al. (10) who reported that Yo-Yo IR1 running performance in temperate conditions $\left(22^{\circ} \mathrm{C}\right)$ was improved on average by $7 \%$ after a training week in 15 soccer players belonging to a Faroe Island first division team and a Danish second division team. The present change in performance therefore may be interpreted as remarkable, especially taking into account that it was achieved in already well-trained professional basketball players.

The results derived from the physical performance tests employed in this study suggested that the tests are highly sensitive to training induced improvements in physical capacity indices. Moreover, it is worth mentioning that the observed improvement in RSA, jumping and running performance need to be contextualized. Basketball is an intermittent activity characterized by frequent, high-intensity actions and changes of directions across short distances (3-4, 32). Basketball also 
incorporates sprints, movements involving accelerations and decelerations and jumps $(3-4,14,32)$. With this in mind, it seems reasonable to assume that the physical tests used in the present study can confidently be adopted in a way within an applied setting to systematically aid training planning.

Together with the physical performance tests, there was a decrease in the players HR responses to the 5 min submaximal run from $\mathrm{T} 1$ to $\mathrm{T} 3$. These noninvasive and non-exhaustive measures of assessing submaximal aerobic capabilities, despite some reported limitations (9) are considered an index of cardiorespiratory fitness, which is strongly correlated with running performance $(7,9)$. In a study with Australian football players, Buchheit et al. (8) demonstrated the usefulness of submaximal HR responses as a monitoring tool during a pre-season period. Buchheit et al. (8) adopted a submaximal $5 \mathrm{~min}$ run/5 min recovery test (7) in order to assess training status of the players. This test was performed at the start of every training session. The intensity of the exercise bout was fixed at $13 \mathrm{~km} \cdot \mathrm{h}^{-1}$ across $40 \mathrm{~m}$ shuttles, and HR response was assessed as previously described (7). In the present study, however, the 5-5 submaximal run was performed at the start of the session with the intensity of the exercise bout fixed at $10 \mathrm{~km} \cdot \mathrm{h}^{-1}$ across $40 \mathrm{~m}$ shuttles. This adaptation in the intensity of the exercise was necessary to maintain the submaximal nature of the test. A pilot study conducted by the present research group before the beginning of this investigation revealed that using the $13 \mathrm{~km} \cdot \mathrm{h}^{-1}$ threshold for the same sample assessed in the present study would lead to elevated fatigue levels thereby compromising the objectives of the test. In summary, the present results of the submaximal test, in conjunction with the physical performance test, suggest the effectiveness of the proposed periodization program. 
The present results also suggest that during the in-season compared to the preseason phase, the specific basketball training sessions presented higher intensity and lower volume. The eTL associated with accelerations and decelerations (mechanical load) increased during in-season despite a reduction in training volume. This is a novel finding, demonstrating empirically that during the competition phase the coaches prescribed training content based mainly on high-intensity actions, in order to mimic real competition demands. During intermittent team sports, players perform numerous accelerations and decelerations both with and without changes of direction (5). Additionally, these types of movements are likely to elicit substantial physical demands and associated physiological responses (35). Indeed, given that basketballspecific actions involve whole-body displacement in forward, backward, lateral and vertical directions, the accelerometer-derived measures are a useful approach to monitor eTL in basketball players (42), and perhaps a more appropriate method to monitor the eTL undertaken by professional basketball players. Additionally, the present findings not only reveal the usefulness of monitoring training by means of mechanical load but these trends could improve our understanding of how professional basketball players train, with special reference to the technical and tactical sessions. This could provide valuable information to coaches on optimizing training during both the pre- and in-season periods.

An important but expected finding of the present investigation concerning monitoring of iTL using session-RPE and TRIMP is that these were affected by "training volume". These findings corroborate previous studies in team-sport athletes that demonstrated the influence of training volume in iTL. For example, Nunes et al. (41) showed that iTL responses of elite female basketball players were aligned with the preprogramed overloading (higher training volume) and tapering phases (lower 
training volume). Indeed, Jeong et al. (24) reported significant higher iTL in the preseason than in season, which reflected the higher volume of training performed during preseason. Additionally, the present results suggest that the increase in training session intensity, mainly due to the increase in actions requiring changes in direction, accelerations and decelerations, high-speed sprints and other related specific basketball actions might lead to a higher mechanical load.

The similar responses among iTL measures suggest that these markers represent a similar construct. However, these relationships are shown to be affected by different types of training sessions in team-sports $(11,30)$. Despite these discrepancies between session-RPE and HR, the results of the present study add to the literature by demonstrating that both iTL and TRIMP markers were not only sensitive to the volume of the training (a relevant marker related to eTL), but also showed higher pre-season values compared to the in-season phase in professional basketball players. It is important to report that the higher iTL and TRIMP values during the preseason phase were expected. (43). It was also expected that the intensity of the technical and tactical sessions would increase during the in-season phase as a reflection of training periodization. This hypothesis was based on the assumption that for team-sports training periodization, a greater training volume would be completed during the pre-season, as demonstrated previously $(24,36)$ and proposed by others (43). Even considering that to date, there are still no comparative studies examining the efficacy of this approach (36), this training content distribution is widely accepted and used by coaches (8).

A major limitation of training intervention studies generally is the lack of a control group (46), and the reader should be aware of this when interpreting the present results. Despite this limitation, the present data confirmed the initial 
hypothesis that the adopted training programme would enhance physical test performances. Additionally, another potential limitation of the current study is the sample size, especially the number of players per position; however, it should be highlighted that due to the difficulty in assessing team sports athletes and the number of athletes belonging to these team, studies in professional team athletes are usually conducted with small sample sizes. For example, Manzi et al. (31) investigated the training load of 8 professional Italian basketball players across 3 different training weeks; Moreira et al. (39) examined the muscle soreness, blood muscle damage markers, muscle strength and agility following an official basketball match in 11 professional women players. Montgomery et al. (35) investigated 11 basketball players in order to characterize the physical and physiological responses of different basketball practice drill and matches. Even recognizing the limitations of using a small sample size in the present study, the results presented here add important empirical observations to the literature, in particular to work related to training periodization, training load and physical responses in elite team sport athletes.

\section{CONCLUSION}

In summary, the present results suggest that the adopted periodization, characterized by a higher pre-season training volume and both higher intensity and increased specific basketball actions during the in-season led to a significant increase in physical performance in professional basketball players. Through analysis of the dynamics of iTL and eTL measures, the results suggest that the "volume" might mainly influence the iTL and, on the other hand, the intensity might considerable affect the eTL measures. Moreover, it can be inferred that fitness status indicators, 
such as HRE and HRR should be used in conjunction with the physical performance test in order to evaluate the effectiveness of the proposed periodization program.

\section{PRACTICAL APPLICATIONS}

The present results indicate that coaches should combine iTL and eTL monitoring approaches to enable a more efficient means of monitoring training load in basketball. Notably, basketball coaches should use the session-RPE method combined with accelerometer derived measures to assess iTL and eTL, respectively, for both preseason and in-season phases. Additionally, coaches should be aware that using the mechanical load, which is an accelerometer-derived measure, would be a very useful approach and even, a more appropriate method to monitor the eTL undertaken by professional basketball players. Finally, the present findings suggest that due to the congruence with the improvement in physical performance and a relevant change in fitness status indicators (HRE and HRR), it appears reasonable to propose these measures to monitor fitness status of professional basketball players. The submaximal nature of the running test is an advantage for use in professional basketball practical settings especially during the in-season phase when practitioners do not want players to perform maximal and exhaustive tests. 


\section{REFERENCES}

1. Arruda AF, Carling C, Zanetti V, Aoki MS, Coutts AJ, and Moreira A. Effects of a very congested match schedule on body-load impacts, accelerations, and running measures in youth soccer players. Int J Sports Physiol Perform 10: 248-252, 2015.

2. Batterham AM and Hopkins WG. Making meaningful inferences about magnitudes. Int J Sports Physiol Perform 1: 50-57, 2006.

3. Ben Abdelkrim N, Castagna C, El Fazaa S, and El Ati J. The effect of players' standard and tactical strategy on game demands in men's basketball. $J$ Strength Cond Res 24: 2652-2662, 2010.

4. Ben Abdelkrim N, El Fazaa S, and El Ati J. Time-motion analysis and physiological data of elite under-19-year-old basketball players during competition. Br J Sports Med 41: 69-75, 2007.

5. Bloomfield J, Polman R, and O'Donoghue P. Physical Demands of Different Positions in FA Premier League Soccer. J Sports Sci Med 6: 63-70, 2007.

6. Boyd LJ, Ball K, and Aughey RJ. Quantifying external load in Australian football matches and training using accelerometers. Int J Sports Physiol Perform 8: 44-51, 2013.

7. Buchheit M, Mendez-Villanueva A, Quod MJ, Poulos N, and Bourdon P. Determinants of the variability of heart rate measures during a competitive period in young soccer players. Eur J Appl Physiol 109: 869878, 2010.

8. Buchheit M, Racinais S, Bilsborough JC, Bourdon PC, Voss SC, Hocking J, Cordy J, Mendez-Villanueva A, and Coutts AJ. Monitoring fitness, fatigue and running performance during a pre-season training camp in elite football players. J Sci Med Sport 16:550-555, 2013.

9. Buchheit M, Simpson MB, Al Haddad H, Bourdon PC, and MendezVillanueva A. Monitoring changes in physical performance with heart rate measures in young soccer players. Eur J Appl Physiol 112: 711-723, 2012.

10. Buchheit M, Voss SC, Nybo L, Mohr M, and Racinais S. Physiological and performance adaptations to an in-season soccer camp in the heat: associations with heart rate and heart rate variability. Scand J Med Sci Sports 21: e477-485, 2011.

11. Campos-Vazquez MA, Mendez-Villanueva A, Gonzalez-Jurado JA, LeonPrados JA, Santalla A, and Suarez-Arrones L. Relationships between rating-of-perceived-exertion- and heart-rate-derived internal training load in professional soccer players: a comparison of on-field integrated training sessions. Int J Sports Physiol Perform 10: 587-592, 2015.

12. Cohen J. Statistical power analysis for the behavioral sciences. Hillsdale: Lawrence Erlbaum, 1988.

13. Coutts AJ and Cormack S. Monitoring the training response. In: HighPerformance Training for Sports. D Joyce, D Lewindon, eds. Champaign, Illinois: Human Kinetics, 2014, pp 71-84.

14. Delextrat A, Badiella A, Saavedra V, Matthew D, Schelling X, and TorresRonda L. Match activity demands of elite Spanish female basketball players by playing position. Int J Perform Anal Sport 15: 687-703, 2015. 
15. Fanchini M, Schena F, Castagna C, Petruolo A, Combi F, McCall A, and Impellizzeri M. External Responsiveness of the Yo-Yo IR Test Level 1 in High-level Male Soccer Players. Int J Sports Med 36: 735-741, 2015.

16. Fitzsimons M, Dawson B, Ward D, and Wilkinson A. Cycling and running tests of repeated sprint ability. Aust J Sci Med Sport 25: 82-87, 1993.

17. Foster C, Daines E, Hector L, Snyder AC, and Welsh R. Athletic performance in relation to training load. Wis Med J 95: 370-374, 1996.

18. Foster C, Florhaug JA, Franklin J, Gottschall L, Hrovatin LA, Parker S, Doleshal $\mathrm{P}$, and Dodge $\mathrm{C}$. A new approach to monitoring exercise training. J Strength Cond Res 15: 109-115, 2001.

19. Hopkins W. Understanding Statistics by Using Spreadsheets to Generate and Analyze Samples, in: Sportscience. 2007, pp 23-36.

20. Hopkins WG. Measures of reliability in sports medicine and science. Sports Med 30: 1-15, 2000.

21. Hopkins WG, Marshall SW, Batterham AM, and Hanin J. Progressive statistics for studies in sports medicine and exercise science. Med Sci Sports Exerc 41: 3-13, 2009.

22. Impellizzeri FM, Rampinini E, Coutts AJ, Sassi A, and Marcora SM. Use of RPE-based training load in soccer. Med Sci Sports Exerc 36: 1042-1047, 2004.

23. Issurin VB. New horizons for the methodology and physiology of training periodization. Sports Med 40: 189-206, 2010.

24. Jeong TS, Reilly T, Morton J, Bae SW, and Drust B. Quantification of the physiological loading of one week of "pre-season" and one week of "inseason" training in professional soccer players. J Sports Sci 29: 11611166, 2011.

25. Johnstone JA, Ford PA, Hughes G, Watson T, and Garrett AT. Bioharness $\left({ }^{\mathrm{T} M}\right)$ multivariable monitoring device: part. I: validity. J Sports Sci Med 11: 400-408, 2012.

26. Johnstone JA, Ford PA, Hughes G, Watson $\mathrm{T}$, and Garrett AT. Bioharness $\left({ }^{\mathrm{TM}}\right)$ Multivariable Monitoring Device: Part. II: Reliability. J Sports Sci Med 11: 409-417, 2012.

27. Johnstone JA, Ford PA, Hughes G, Watson T, Mitchell AC, and Garrett AT. Field based reliability and validity of the bioharness multivariable monitoring device. J Sports Sci Med 11: 643-652, 2012.

28. Krustrup P, Mohr M, Amstrup T, Rysgaard T, Johansen J, Steensberg A, Pedersen PK, and Bangsbo J. The yo-yo intermittent recovery test: physiological response, reliability, and validity. Med Sci Sports Exerc 35: 697-705, 2003.

29. Leard JS, Cirillo MA, Katsnelson E, Kimiatek DA, Miller TW, Trebincevic K, and Garbalosa JC. Validity of two alternative systems for measuring vertical jump height. J Strength Cond Res 21: 1296-1299, 2007.

30. Lovell TW, Sirotic AC, Impellizzeri FM, and Coutts AJ. Factors affecting perception of effort (session rating of perceived exertion) during rugby league training. Int J Sports Physiol Perform 8: 62-69, 2013.

31. Manzi V, D'Ottavio S, Impellizzeri FM, Chaouachi A, Chamari K, and Castagna C. Profile of weekly training load in elite male professional basketball players. J Strength Cond Res 24: 1399-1406, 2010. 
32. McInnes SE, Carlson JS, Jones CJ, and McKenna MJ. The physiological load imposed on basketball players during competition. J Sports Sci 13: 387397, 1995.

33. Meckel Y, Gottlieb R, and Eliakim A. Repeated sprint tests in young basketball players at different game stages. Eur J Appl Physiol 107: 273279, 2009.

34. Miloski B, Aoki MS, de Freitas CG, Schultz de Arruda AF, de Moraes HS, Drago G, Borges TO, and Moreira A. Does Testosterone Modulate Mood States and Physical Performance in Young Basketball Players? J Strength Cond Res 29: 2474-2481, 2015.

35. Montgomery PG, Pyne DB, and Minahan CL. The physical and physiological demands of basketball training and competition. Int J Sports Physiol Perform 5: 75-86, 2010.

36. Moreira A, Bilsborough JC, Sullivan CJ, Ciancosi M, Aoki MS, and Coutts AJ. Training periodization of professional Australian football players during an entire Australian Football League season. Int J Sports Physiol Perform 10: 566-571, 2015.

37. Moreira A, Crewther B, Freitas CG, Arruda AF, Costa EC, and Aoki MS. Session RPE and salivary immune-endocrine responses to simulated and official basketball matches in elite young male athletes. J Sports Med Phys Fitness 52: 682-687, 2012.

38. Moreira A, McGuigan MR, Arruda AF, Freitas CG, and Aoki MS. Monitoring internal load parameters during simulated and official basketball matches. J Strength Cond Res 26: 861-866, 2012.

39. Moreira A, Nosaka K, Nunes JA, Viveiros L, Jamurtas AZ, and Aoki MS. Changes in muscle damage markers in female basketball players. Biol Sport 31: 3-7, 2014

40. Mujika I. Intense training: the key to optimal performance before and during the taper. Scand J Med Sci Sports 20 Suppl 2: 24-31, 2010.

41. Nunes JA, Moreira A, Crewther BT, Nosaka K, Viveiros L, and Aoki MS. Monitoring training load, recovery-stress state, immune-endocrine responses, and physical performance in elite female basketball players during a periodized training program. J Strength Cond Res 28: 2973-2980, 2014.

42. Scanlan AT, Wen N, Tucker PS, and Dalbo VJ. The relationships between internal and external training load models during basketball training. $J$ Strength Cond Res 28: 2397-2405, 2014.

43. Schelling X and Torres-Ronda L. Conditioning for Basketball: Quality and Quantity of Training. Strength Cond J 35: 89-94, 2013.

44. Scott BR, Lockie RG, Knight TJ, Clark AC, and Janse de Jonge XA. A comparison of methods to quantify the in-season training load of professional soccer players. Int J Sports Physiol Perform 8: 195-202, 2013.

45. Smith DJ. A framework for understanding the training process leading to elite performance. Sports Med 33: 1103-1126, 2003.

46. Stone MH and Sands WA. The Downfall of Sports Science in the United States. Strength Cond J 26: 72-75, 2004.

47. Winter EM, Abt GA, and Nevill AM. Metrics of meaningfulness as opposed to sleights of significance. J Sports Sci 32: 901-902, 2014. 


\section{ACKNOWLEDGEMENTS}

We would like to thank all the basketball players and research support staff involved in this study for their committed participation, particularly the head coach, Marcel de Souza.

\section{Figure Legends}

Figure 1. Standardized changes in mean (Cohen units) in physical performance measures. Error bars indicate uncertainty in the true mean changes with $90 \%$ confidence limits. The shaded area on the graph denote the smallest worthwhile change. $\mathrm{HRE}=$ hear rate exercise; HRR $=$ heart rate recovery; Yo-Yo $=$ Yo-yo intermittent recovery test level 1 ; CMJ = countermovement jump; $\mathrm{SJ}=$ squat jump; $\mathrm{T} 1=$ test $1 ; \mathrm{T} 2=$ test $2 ; \mathrm{T} 3=$ test 3 . The number of ' $*$ ' symbol refers to the likelihood of the changes (*: possibly, ${ }^{* *}$ : likely, $* * *$ : very likely).

Figure 2. Training load data (session-RPE $x$ min; AU) across the 11-week microcycles during both pre- (weeks 1 to 6) and in-season (weeks 7 to 11) phases (technical and tactical training sessions).

Figure 3. Internal training load and session-RPE values for physical training during the 11-week training period

\section{Tables legends}

Table 1. Typical daily training aims during pre- and in-season

Table 2. Typical daily physical training exercises during pre-season $\left(1^{\text {st }}\right.$ and $2^{\text {nd }}$ preseason periods) and in-season phases represented by week 2 , week 5 , and week 8 , respectively.

Table 3. Descriptive analysis for physical performance

Table 4. Descriptive analysis for internal and external load variables and differences between training phases (pre-season and in-season).

Table 5. ITL - Physical training; Descriptive values expressed as average per week. 
Table 1. Typical daily training content during pre- and in-season phases

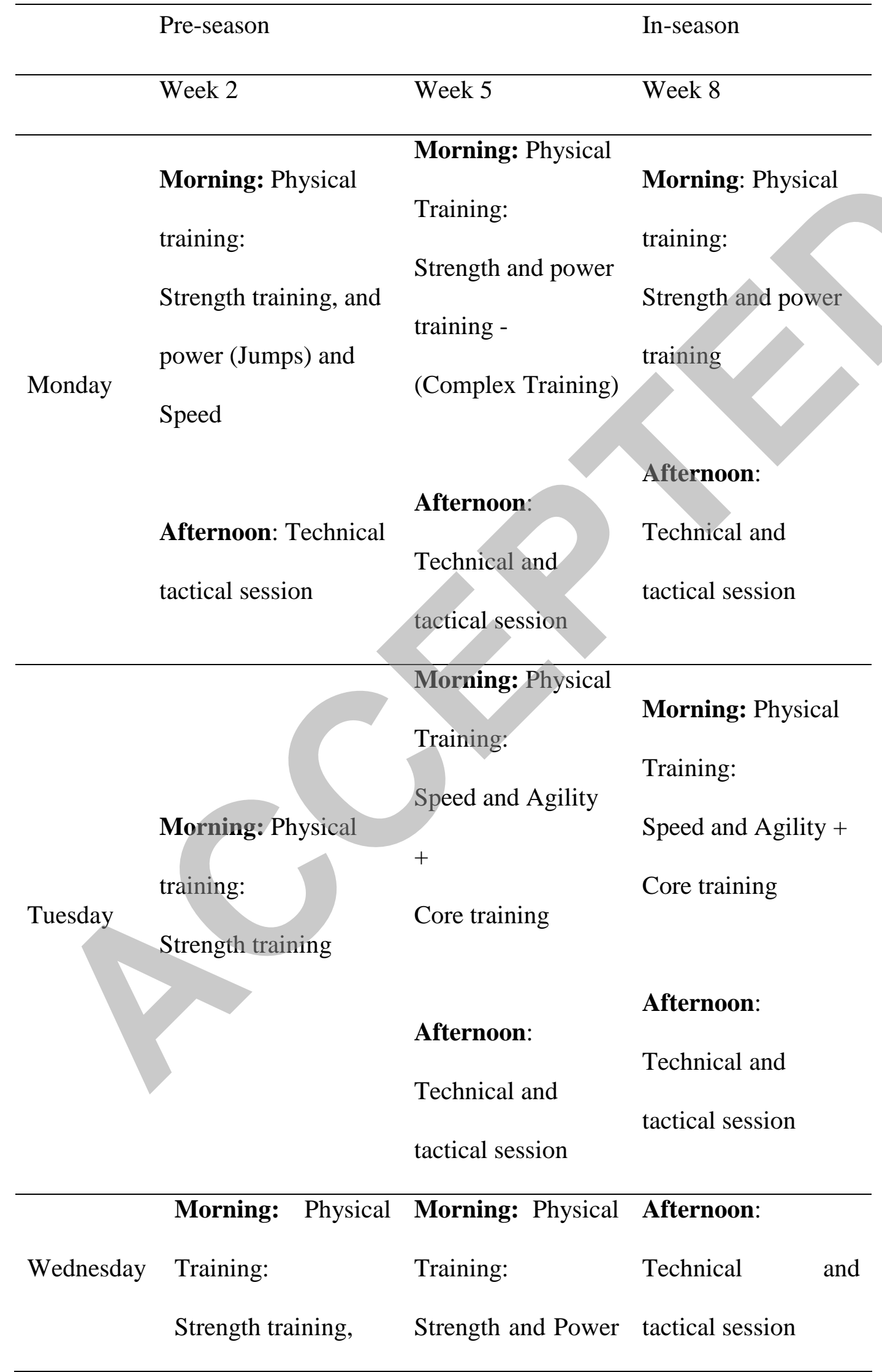




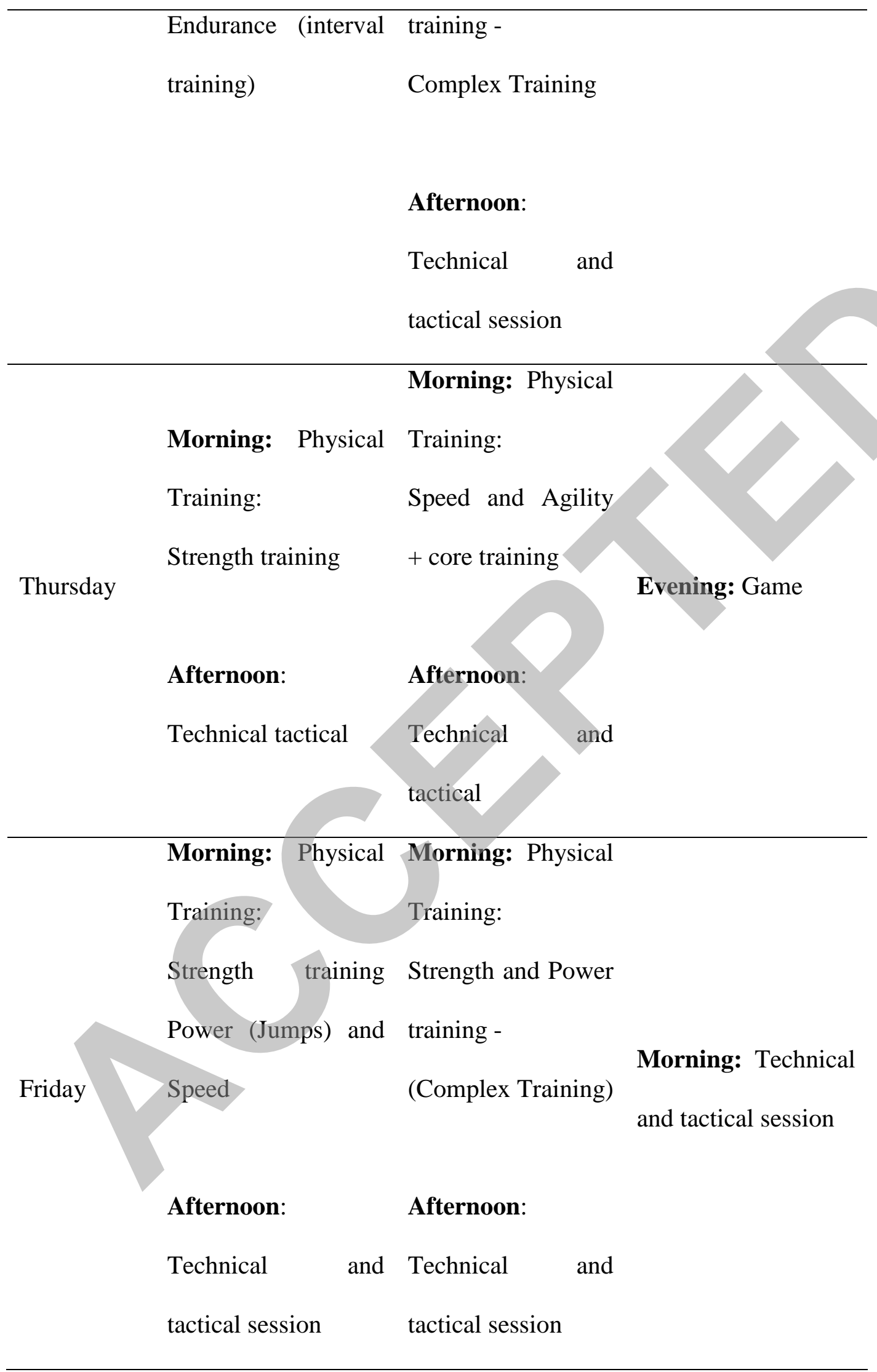




\section{Morning: Physical}

Training:

Saturday Strength training, Rest Evening: Game

Endurance (interval

training)

Sunday Of

Off

Off 
Table 2. Typical daily physical training exercises during pre-season $\left(1^{\text {st }}\right.$ and $2^{\text {nd }}$ pre-season periods) and in-season phases represented by week 2 , week 5 , and week 8, respectively.

MONDAY, WEDNESDAY, FRIDAY

TUESDAY, THURSDAY, SATURDAY

MONDAY, WEDNESDAY, FRIDAY

TUESDAY, THURSDAY, SATURDAY

MONDAY, WEDNESDAY, FRIDAY

\section{Week 2}

Strength training (4-5 sets $\mathrm{x} 12 \mathrm{RM})$

Hamstring Leg Curl, Hip Adductor, Hip Abductor, Forehead

Triceps, pulley Triceps, Dumbbell Biceps Curl, W bar biceps Curl.

Power (4 sets x 4 reps; maximal velocity)

Hurdle Jump, Hurdle Jump with Fright, hurdle one-step, Jump,

Barrier Lateral jump.

Speed (6-8 sets $\times 10-15$ meters; running with speed variation)

Endurance (interval training) - Interval Training 8-10 × 2' running: 30 " rest*

*only on WEDNESDAY

Strength training (4-5 sets $\mathrm{x} 12 \mathrm{RM})$

Deeps Squats 2-4x12, Leg Press, Leg Curl, Dead Lift

Machine, Bench Press, Pull-Up

Endurance (interval training) *

\section{* Only on Saturday}

Week 5

Strength and power training - (Complex Training)

Split Squat 2-3x8, Weightlifting: Clean 3-4x6 (Power), Leg

Press 3-4x6RM + Hurdle Jump 3-4x2, Dead Lift 3-4x6RM +

Hurdle Jumps 3-4x2, Bench Press 3-4x6RM + Chest Medicine

ball throwing 3-4x4

Jumping Push-ups 3-4x6

Speed and Agility

Sprint $6-8 \times 15-20 \mathrm{~m}$, Sprint with 1-2 changes of direction $8-10 \times 20$ $25 \mathrm{~m}$

Core training: Elbow Plank 3x60", Side Plank 3x60", Sit-Up 4x15

\section{Week 8}

Strength and power training

Split Squat 2x8RM, Weightlifting: Clean 3x4 (Power), Leg Press 34x6RM 
Dead Lift 3-4x6RM, Bench Press 3-4x6RM, Hurdle Jump 3-4x2, Box Jumps 3-4x2, Medicine ball chest throwing 3-4x4, Jumping Push-ups 3-4x6

TUESDAY, THURSDAY, SATURDAY
Speed and agility

Footwork ladder agility 4-5x, Sprint 4-5x10m Sprint, Change of direction Drills 4-5x15m, Core training: Full Plank 3x60", Side Rotation Plank 3x60"

V-Seat with trunk rotation $4 \times 15$ 
Table 3. Descriptive analysis for physical performance

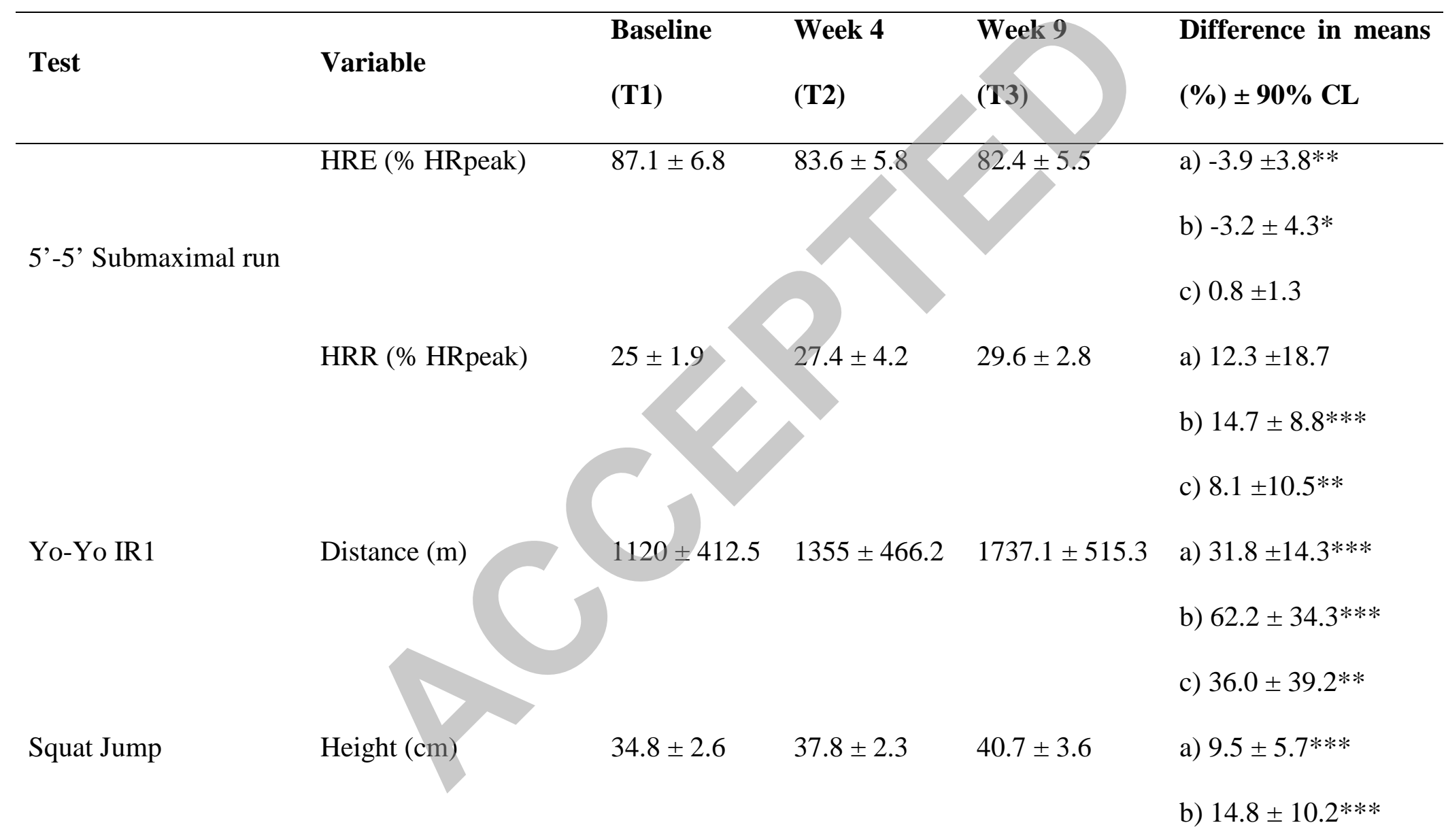




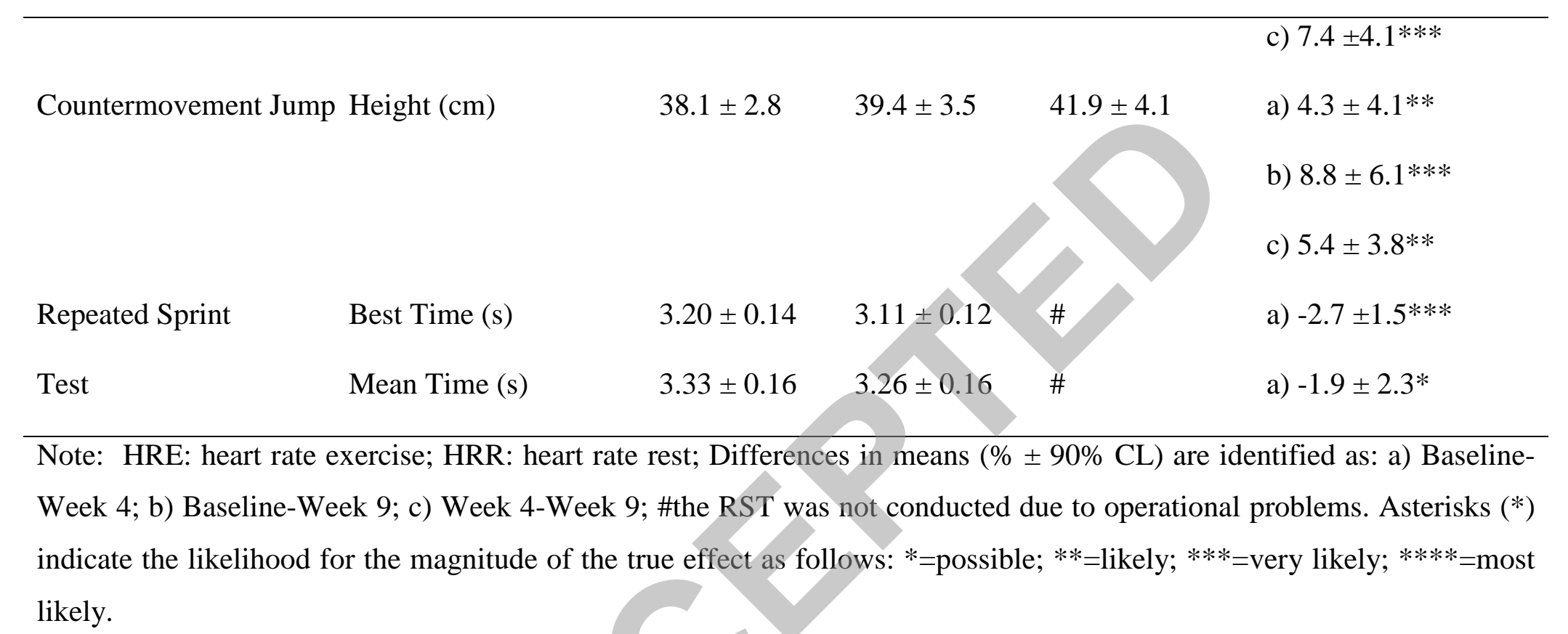


Table 4. Descriptive analysis for internal and external load variables and differences between training phases (pre-season and in-season).

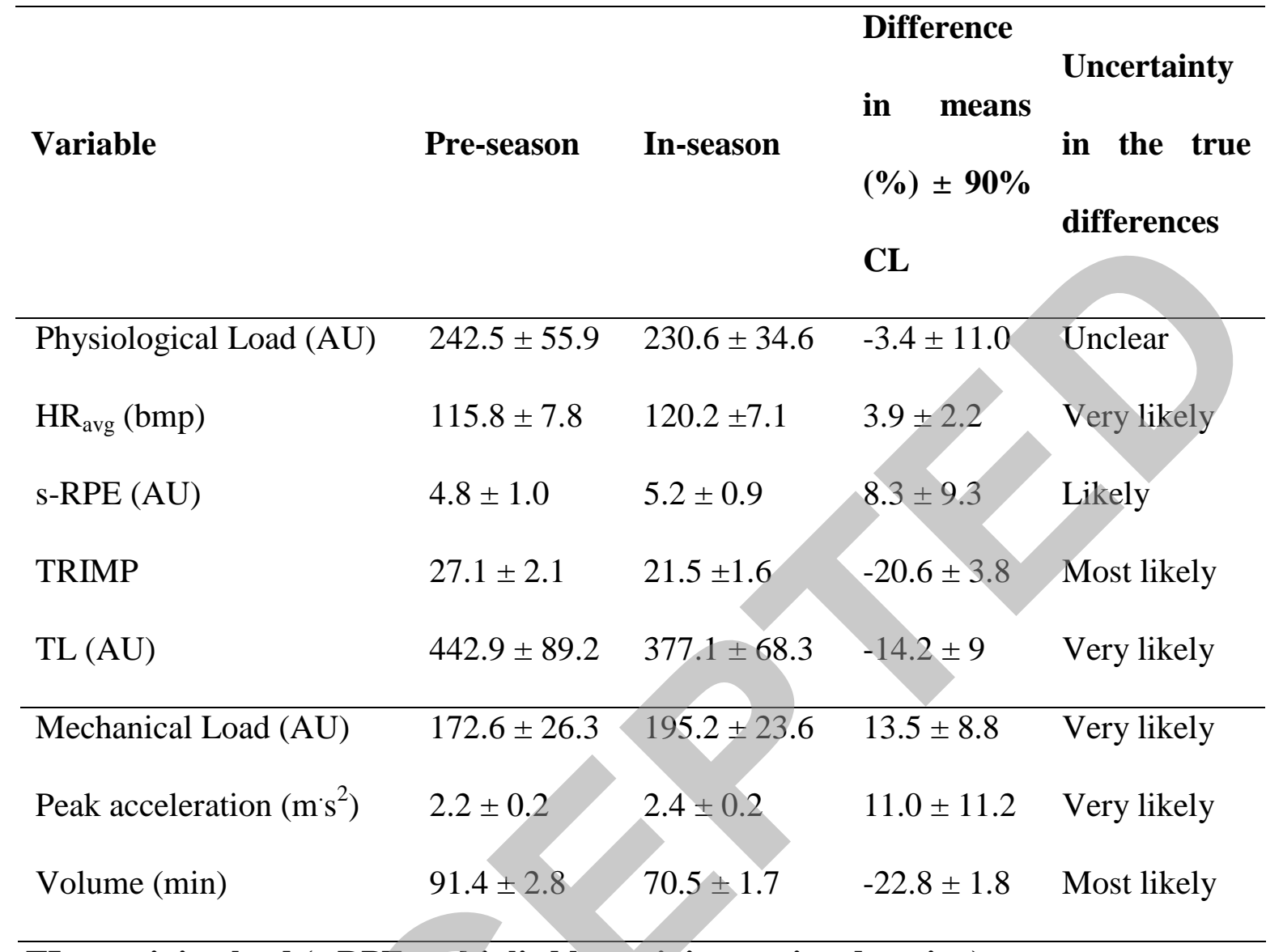

TL = training load (s-RPE multiplied by training session duration) 
Table 5. ITL - Physical training; Descriptive values expressed as average per week.

\begin{tabular}{lllll}
\hline \multicolumn{1}{c}{ Variable } & Pre-Season & Pre-Season & Pre-season & In-season \\
& First Period & Second Period & & \\
\hline Accumulated iTL (AU) & $3591.3 \pm 877.6$ & $1724.8 \pm 347.7$ & $2621.2 \pm 545.1$ & $754 \pm 110.3$ \\
Average iTL (AU) & $638.7 \pm 127.3$ & $357.9 \pm 56.9$ & $489.4 \pm 85.6$ & $251.3 \pm 29.1$ \\
s-RPE (AU) & $6.3 \pm 1.1$ & $5.2 \pm 0.9$ & $5.7 \pm 0.9$ & $4.8 \pm 0.7$ \\
\hline
\end{tabular}




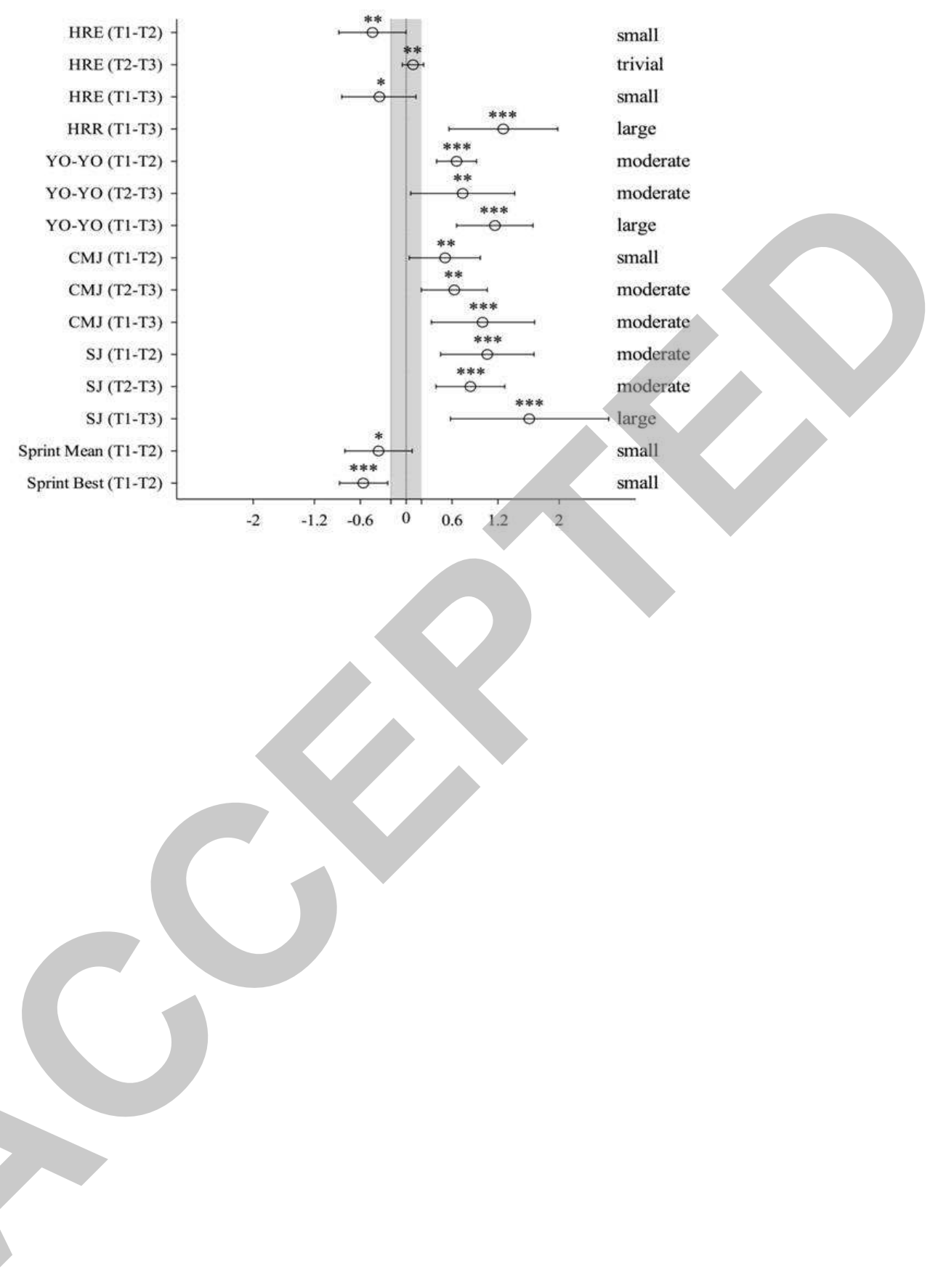




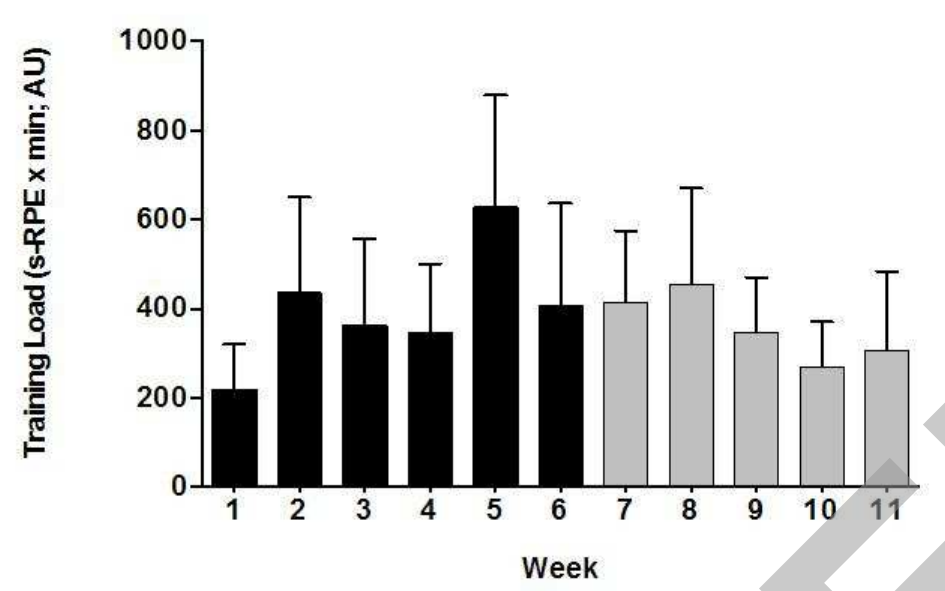




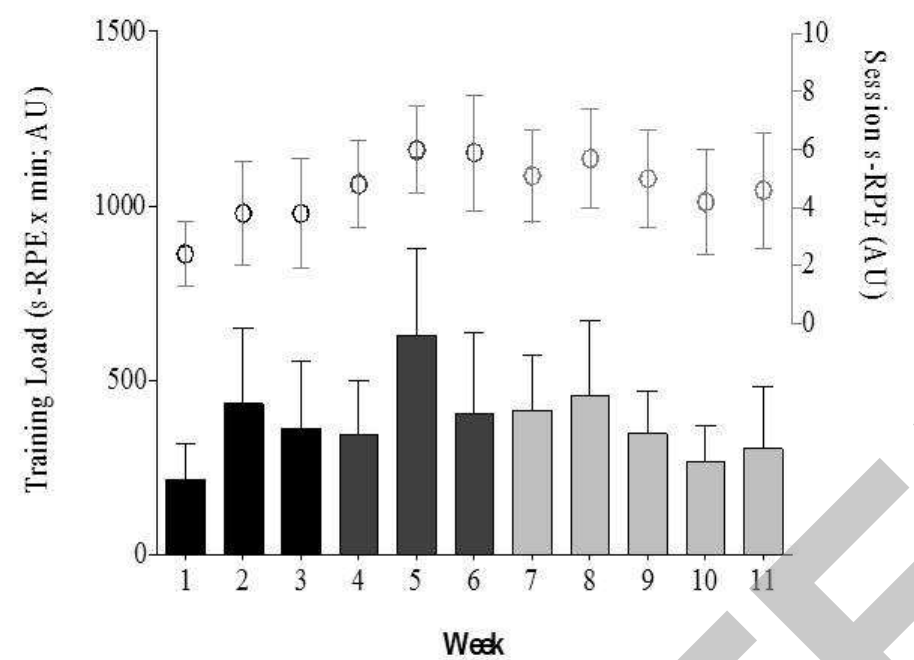

